\title{
Desde la Quimera a la Realidad: haciendo operativa la sostenibilidad estratégica en destinos turísticos ${ }^{1}$
}

\section{From the Chimera to the Reality: making the strategic sustainability in tourist destinies operative}

\author{
Rosana Mazaro ${ }^{2}$
}

\begin{abstract}
Resumen
Los condicionantes y determinantes del desarrollo turístico en el ámbito de los destinos apuntan hacia la convergencia entre los atributos de competitividad y de sostenibilidad. Desde una perspectiva de la planificación y de gestión es notable el esfuerzo en conocer y evaluar las reales condiciones competitivas de los destinos para orientar las decisiones hacia posiciones favorables y duraderas. Este artículo es parte del proceso de maduración de una propuesta metodológica denominada Comp\&tenible Model, aplicable en la evaluación de la sostenibilidad estratégica de destinos turísticos, caracterizada por atributos que reflejan un entorno de competitividad globalizada y de esfuerzos por la implementación de modelos de desarrollo turístico en el marco de la sostenibilidad. Como ejercicio de su validación se presenta los hallazgos de la aplicación en el destino Archipiélago Fernando de Noronha, Brasil.
\end{abstract}

Palabras claves: competitividad; destinos turísticos; sostenibilidad estratégica

\begin{abstract}
The conditioners and determinants of the touristic development in the scope of the destinies aim towards the convergence between the sustainability and competitiveness attributes. From the planning and managing perspective, efforts to know and evaluate the real competitive conditions of destinies oriented to decisions towards advantageous positions and lasting is remarkable. This article is part of the process of maturation of a methodology proposal denominated Comp\& tenible Model, applicable in the evaluation of the strategic sustainability of tourist destinies, characterized by attributes that reflect surroundings of globalised competitiveness and efforts within the framework of implementing models for sustainable tourism development. As a validation exercise it presents the results its application in the destiny Archipelago Fernando de Noronha, Brazil.
\end{abstract}

Keywords: competitiveness; touristic destinies; strategic sustainability

\section{Resumo}

Os condicionantes e determinantes do desenvolvimento turístico para os destinos turísticos apontam para a convergencia entre os atributos de competitividade e de sustentabilidade. A

\footnotetext{
1 Trabalho apresentado no X Seminario Internacional de Turismo em Curitiba, Brasil.

2 Doutorado em Administração/Turismo pela Universidade de Barcelona- DITMUB, Espanha. Mestrado em Administração pelo PPGA/UFSC. Graduada em Administração. Coordenadora do Programa de Pós-Graduação em Turismo-PPGTUR/UFRN. Coordenadora do Grupo Interdisciplinar de Pesquisa em Turismo e Sociedade.BITS. E-mail: rosanamazaro@uol.com.br
} 
partir de uma perspectiva do planejamento e da gestão nota-se um esforço em conhecer e avaliar as reais condições competitivas dos destinos a fim de orientar decisões rumo a um posicionamento favorável e duradouro. Este artigo faz parte do proceso de amadurecimento de uma proposta metodológica denominada Comp\&tenible Model, que se aplica para avaliação da sustentabilidade estratégica de destinos turísticos, caracterizada por atributos que refletem um ambiente de competitividade globalizada e de esforços para a implementação de modelos de desenvolvimento turístico com base em referenciais sustentáveis. Como exercicio para sua validação, são apresentados os resultados da aplicação no destino Arquipélago Fernando de Noronha, Brasil.

Palavras-chave: competitividade; destinos turísticos; sustentabilidade estratégica.

\section{Introducción}

El aumento de la competencia entre destinos, los cambios en el comportamiento y en las exigencias de los consumidores, unido a la mayor profesionalización de los diferentes agentes turísticos, requieren la aplicación de instrumento estratégicos y de gestión turística capaces de mantener y mejorar la competitividad turística local, satisfacer a los clientes de forma rentable y contribuir para la mejora en la calidad de vida de la población (BOSCH ET AL., 1998; RITCHIE y CROUNCH, 2003).

El avance en la comprensión de los factores que determinan la competitividad de los destinos turísticos y principalmente la inclusión de criterios de sostenibilidad como condicionantes estratégicos, han ocasionado distintos modelos teóricos que intentan representar el complejo sistema donde se plasma el turismo y toda su implicada trama de actividades. Estos modelos logran establecer las principales variables que intervienen en la competitividad turística en una perspectiva local - de destino turístico - y coinciden en la predicción de los factores y atributos del paradigma del turismo sostenible como pautas estratégicas para su planificación, organización y gestión. (GO y GOVERS, 2000).

En ellos, el turismo es interpretado como fenómeno socioeconómico que manifestase en un proceso dinámico y conformado en una secuencia lógica de decisiones y acciones interrelacionadas e interdependientes, que pueden ser identificadas y caracterizadas por medio de un conjunto de factores que ejercen fuerza determinante para el alcance de una condición de éxito competitivo - conquistar resultados superiores en requisitos claves del segmento turístico y a la vez, éxito sostenible - de impactos positivos en la calidad de vida de la localidad (GOOROOCHURN y SUGIYARTO, 2003). 
Tras el análisis sistemática del contenido de estos modelos, es posible afirmar que las principales dimensiones, elementos, mecanismos y indicadores de evaluación de las condiciones de competitividad están señalizadas en las sus representaciones, y se destaca el hecho de los factores efectivamente determinantes de estas condiciones, aunque con nominaciones distintas, están contemplados en todos los formatos de interpretación teórica del tema, indicando las fuerzas y las debilidades para enfrentarse al contexto de la competencia entre destinos turísticos. Asimismo, se revela un contundente consenso entre los científicos en lo que toca a los factores de consideración estratégica para la gestión sostenible del turismo local.

Sin embargo, entendiendo el turismo como un sistema abierto, complejo y multifacético, las aproximaciones teóricas y los intentos de monitoreo de competitividad y de sostenibilidad que se basan en análisis compartimentados de las dimensiones medioambiental, económica y social, ya no son suficientes para permitir la comprensión de su real dinámica, de las interrelaciones entre los factores de cada dimensión y de la evolución en el tiempo del proceso de desarrollo turístico de forma integral e integrada, en conformidad al principio de los sistemas abiertos.

Desde la perspectiva de la gestión del turismo en los destinos, es fundamental comprehender su dinámica en conformidad a su proceso de manifestación en la realidad, o sea, entender el cómo y dónde se manifiestan las variables consideradas en sus análisis y principalmente la motricidad de las mismas, para que se pueda explicar el que determina los resultados e impactos y el peso de las decisiones sobre ellos. Esto contexto exige un replanteamiento de las premisas que han orientado su desarrollo hasta entonces, como son las prioridades políticas locales, la conformación de los procesos de toma de decisiones y las estrategias organizacionales y locales.

El Competenible Model es fruto del marco teórico de convergencia de estos temas y se anãde al esfuerzo en contribuir para hacerse cumplir las premisas sobre las cuales reposa el paradigma sostenible y orientar hacia el planeamiento turístico y su implementación a través de acciones que correspondan a las expectativas de la competitividad y sostenibilidad turística local (RITCHIE y CROUCH, 2000 y 2003).

El articulo resumen un ejercicio de aplicación del modelo y refleja la evaluación de las condiciones concretas de competitividad y de sostenibilidad en el destino turístico de Fernando de Noronha, Brasil, en el intento de mejor comprensión del como estos factores se manifiestan y, por lo tanto, como pueden ser manejados para que produzca los resultados e 
impactos deseados por la gestión, a fin de confirmar la viabilidad y capacidad efectiva de fijar modelos más equilibrados de desarrollo turístico y local

\section{Metodología de Investigación y de Validación del Modelo}

La proposición teórica del Competenible Model estuvo ancorada en la metodología de la modelación. En los argumentos de Gilbert y Boulter (1995), los modelos son inherentes a la producción, divulgación y aceptación del conocimiento generado por la ciencia, actuando como un puente entre las teorías científicas y la realidad. Las principales funciones atribuidas a los modelos se puede ordenar en: - orientan la observación y el estudio; - facilitan la comprensión; - explican factores; - facilitan el entendimiento de las funciones; - facilitan el establecimiento de relaciones y funciones; - describen condiciones; - posibilitan generalizaciones (BROWN, 1994).

"La importancia de los modelos en la investigación científica radica en que a través de ellos, los científicos formulan cuestiones acerca del mundo, describen, interpretan y explican fenómenos, elaboran hipótesis y testan su validez y realizan predicciones” (GOBERT y BUCKLEY, 2000). La modelación en escala local objetiva evaluar la sustentabilidad de destinos turísticos in situ, suministrando a los agentes del turismo, investigadores y mediadores sociales informaciones sobre la realidad en la cual actúan y contribuyendo para que esos actores sociales formulen proyectos y políticas de desarrollo en base a informaciones objetivas y concretas.

Los atributos, que representan las variables a investigar, son comprendidos por el modelo como manifestaciones objetivamente observables y mesurables de los conceptos que representan, o sea, “huellas visibles de la realidad” (QUIVY y CAMPENHOUDT, 1998, p.122). Los criterios de valoración aplicados en el modelo fueron seleccionados de la literatura que trata de los fundamentos sostenibles y de las condiciones básicas para su aplicación al éxito competitivo (MAZARO y VARZIN, 2005). Todos los atributos se refieren al entorno propio del destino turístico, o sea, no hay indicadores de escala global, apenas local. Son utilizados para hacer operativos los conceptos y definir padrones - el desarrollo, la competitividad y la sostenibilidad.

Además de seleccionar y definir los atributos, el modelo atribuye valor a estos factores, que en esto caso significa arbitrar numéricamente estándares de referencia que sirvan de medida 
de comportamiento del factor, de acuerdo con padrones de éxito competitivo extraídos de datos reales (QUIVY y CAMPENHOUDT, 1998).

Consideró que para los atributos significativos o determinantes para el funcionamiento del sistema, es posible establecer estándares de desempeño y comportamiento superiores que sirvan como referenciales para el establecimiento de los objetivos en el planeamiento y gestión del turismo local. Los atributos cuantitativos son, en principio, más objetivos que los cualitativos y permiten realizar una mejor comparación entre los diferentes casos. Sin embargo, la elección entre atributos cuantitativos y cualitativos a veces se encuentra determinada por la falta de datos o por la necesidad de realizar estudios in situ. Por ello, los datos cualitativos resultarán los únicos disponibles (MAZARO, 2006).

Más importante, todavía, es que la aplicación en este formato permitirá acompañar la evolución del destino en sus avances y retrocesos de cara a los estados-estándares y a lo largo del tiempo, cumpliendo así, con uno más de los objetivos planteados en esta proposición.

Goode y Hatt (1977) señalan que las técnicas de escalonamiento se aplican cuando el problema es ordenar una serie de ítems a lo largo de un continuo. O sea, son métodos dedicados a transformar una serie de datos cualitativos (atributos) en una serie cuantitativa (estándares de desempeño). El elemento matemático confiere a la evaluación mayor precisión, además, por medio de la aplicación de la técnica de medidas graduadas, se alcanza a precisar con cierta exactitud en cuanto el destino se acerca o se aleja del estado ideal de sostenibilidad estratégica.

En efecto, la capacidad de permitir que se comparen resultados a lo largo del tiempo, es decir, la evolución del comportamiento de cada factor y a la vez, valorar una condición general del destino, hace del modelo un instrumento de predicción y gestión.

\section{Haciendo Operativa la Sostenibilidad Estratégica en Destinos Turísticos}

La complejidad inherente a fenómenos como desarrollo, competitividad y sostenibilidad turística exige visión multidisciplinar y gestión estratégica. Por otra parte, establecer niveles satisfactorios y evaluar competitividad y sostenibilidad es factor crucial a la hora de plantearse éxito en los destinos turísticos. Bajo una perspectiva integral e integrada, el sistema turístico de un destino es aquí interpretado a través de tres dimensiones de análisis, que se han estructurado como equivalentes a las etapas secuenciadas del ciclo o flujo sistémico del proceso de decisiones y acciones que determina la evolución del turismo en el ámbito local. 
Igualmente, desde la óptica del planeamiento y gestión de los destinos, el modelo de referencia que se aplica en este estudio hace hincapié en el análisis de los procesos de definición y implementación de las estrategias y acciones planteadas, o sea, en el cómo se hacen las cosas, una vez que la lectura e interpretación de los elementos del modelo presuponen una relación de causa-efecto. En el modelo los atributos evaluados en la dimensión desarrollo son los catalizadores de los procesos de sostenibilidad turística y funcionan como traductores del nivel de madurez y profesionalismo en la configuración de políticas turísticas en el ámbito local, fijando así el modelo de desarrollo turístico definido para el destino (VALLS, 2004).

La dimensión competitividad turística comprende atributos que reflejan los resultados del sector turístico en el destino, definidos y evaluados a partir de representaciones de las condiciones ideales de competitividad que pueden alcanzar en términos referenciales de mercado, a efecto de las estrategias de gestión y coordinación implementadas hacia su desarrollo (OCDE, 2003; WTTC, 2004).

La dimensión sostenibilidad turística se preocupa por los impactos más amplios del turismo sobre el ambiente y la sociedad en un horizonte temporal a largo plazo. El impacto es la consecuencia de la relación causa-efecto ya comentada en los criterios de eficiencia. En general, está relacionado a posibles transformaciones que pueden venir a sufrir determinado sistema a causa de interferencias externas deliberadas. Diferentemente de los resultados, que revelan un momento determinado, los impactos solo pueden ser evaluados por atributos que permitan analizar la evolución del comportamiento del factor en el tiempo, considerando que efectos de largo-plazo solamente pueden hallarse tras pasado esto largo plazo, y a partir de un punto de referencia en el pasado (JACOBS, 1997).

Estas dimensiones del sistema turístico local están formateadas y denominadas en el Comp\&tenible Model $^{\mathrm{i}}$ como representado en la Figura 1. 


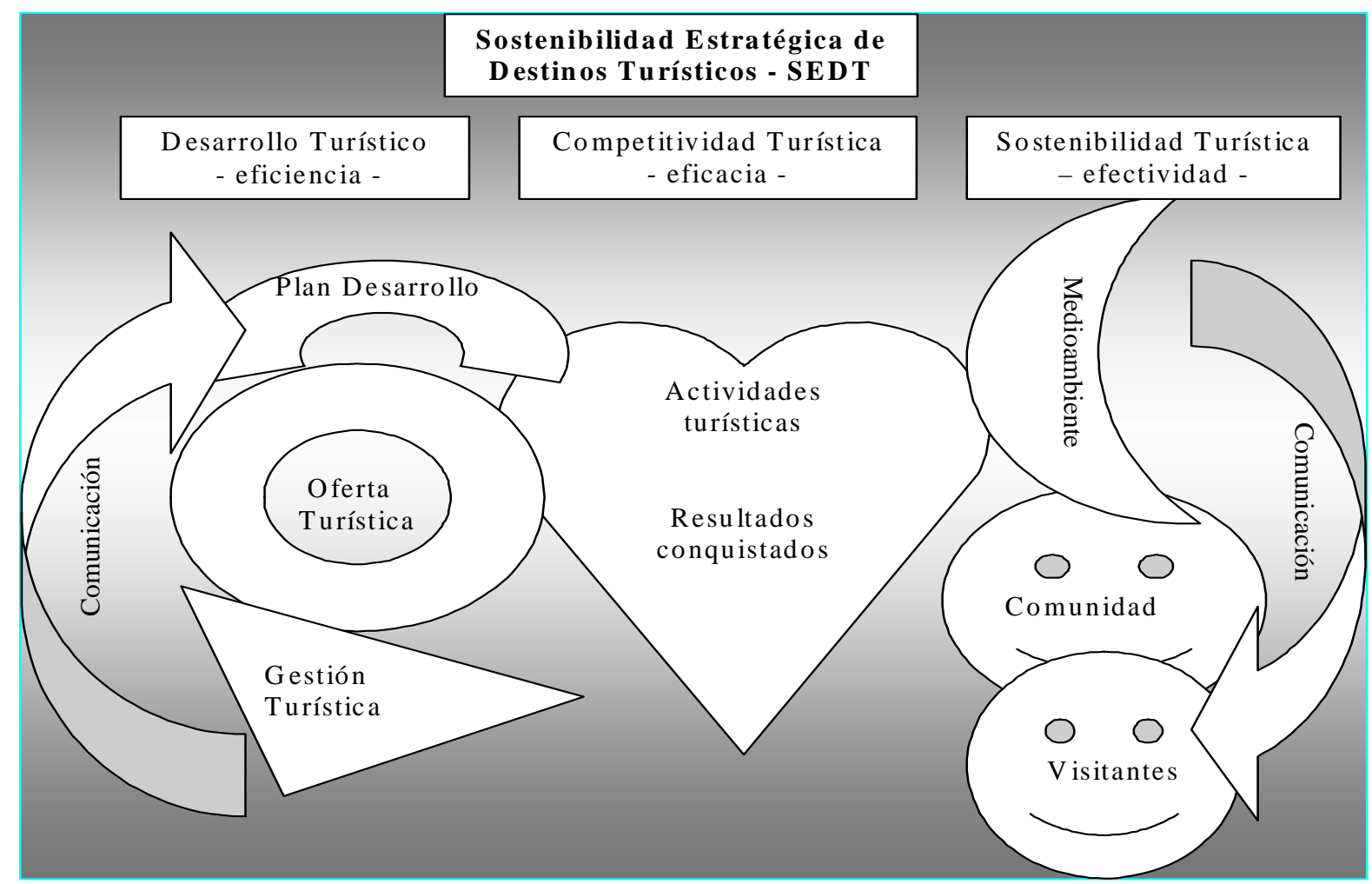

Figura 1. Sistema Turístico del Destino por el Comp\&tenible Model

Fuente: Elaboración propia (2004)

De esta forma, la evolución de los niveles de desarrollo, competitividad y sostenibilidad de los destinos turísticos, que aquí se convergen en lo que se denomina sostenibilidad estratégica, es posibilitada por el monitoreo de un conjunto de factores determinantes del éxito en cada dimensión y cuyos resultados sean capaces de indicar las condiciones bajo las cuales se desarrolla el turismo en un destino especifico y que permita acompañar su evolución en el tiempo.

Las tres dimensiones - desarrollo, competitividad y sostenibilidad - sugestionan una clara secuencia lógica, sistémica y interdependiente de etapas que se han de cumplir los destinos hacia el éxito estratégico y que fueran comprobadas como apropiadas y efectivas en la explicación del proceso del desarrollo turístico local, confirmando la premisa que los resultados logrados y los impactos de largo plazo provocados es positivamente consecuencia del modelo fijado para que el desarrollo turístico acontezca.

Sintéticamente, estas condiciones se resumen como indicado en la Tabla 1. 
Tabla 1 - Valoración Global: Sostenibilidad Estratégica del Destino (SEDT)

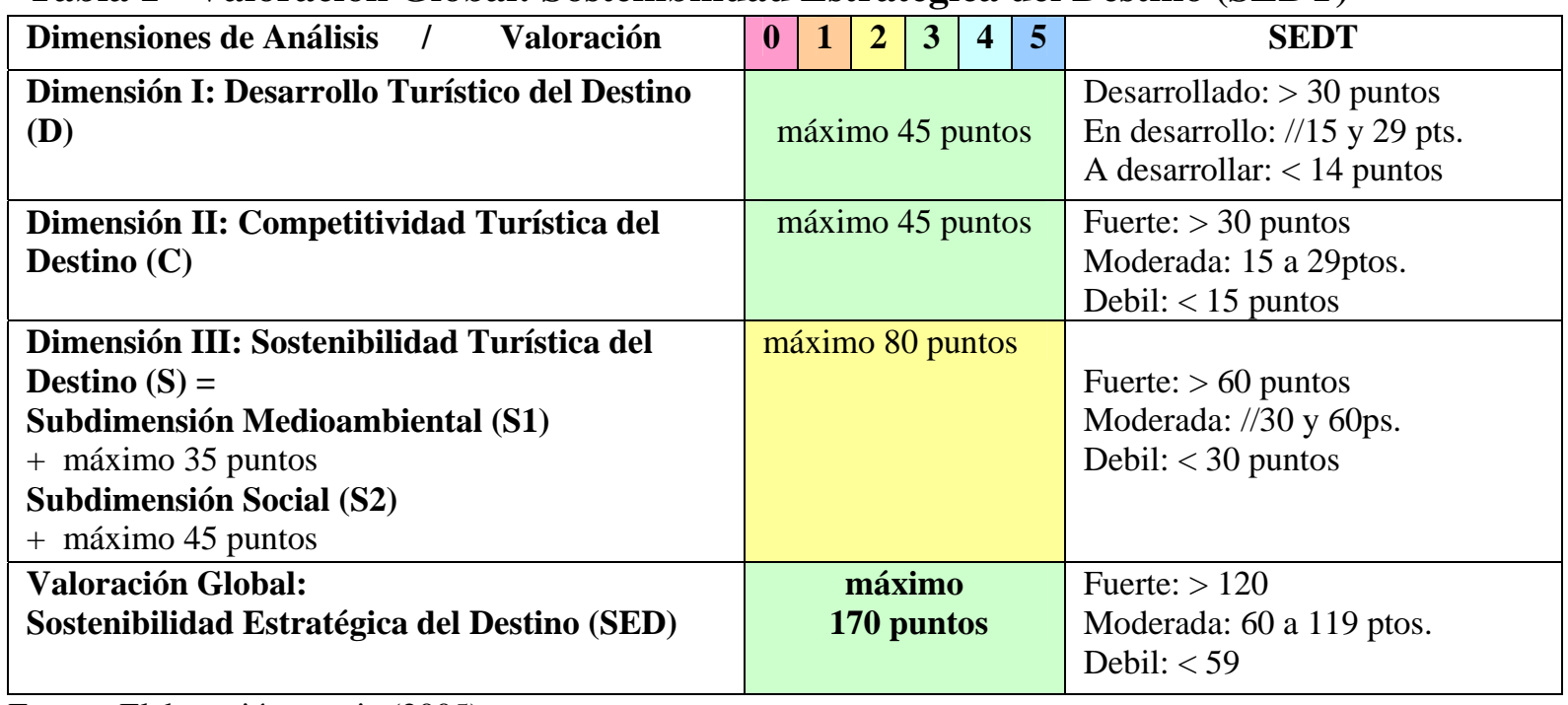

Fuente: Elaboración propia (2005)

La intención es sumar esfuerzos en hacer operativos los modelos de orientación hacia la gestión y planificación turística de destinos en clave a los determinantes competitivos globales y a los condicionantes sostenibles estratégicos y de consolidar un modelo metodológico que, a parte de apuntar de forma lógica y sistémica los factores de influencia sobre el desarrollo del turismo y agrupar-se-los en dimensiones de análisis que presupone un proceso continuado de decisiones y acciones, posibilite evaluar el estado o nivel de éxito en cada uno de ellos y en el conjunto de variables que condicionan el estado de sostenibilidad estratégica del destino turístico.

\section{Aplicación del Comp\&tenible Model: evaluación de la sostenibilidad estratégica en el} destino Fernando de Noroña

Como parte del necesario camino hacia la validación del modelo, se ha evaluado el destino turístico de Fernando de Noroña utilizando el diagrama que representa el Comp\&tenible Model. A continuación se presentan los resultados de su aplicación en aquello Archipiélago, importante y singular destino turístico ubicado en el extremo nordeste de Brasil, provincia de Pernambuco.

\subsection{Dimensión I - desarrollo turístico de Fernando de Noroña}

Fernando de Noroña es un caso único en la estructura administrativa de la República Federativa de Brasil y su desarrollo turístico es muy reciente. La economía local, que hasta la 
década de los ochenta estaba íntegramente subvencionada por el Gobierno Central, ha sufrido un rápido proceso de transición y de golpe tuvo que enfrentarse a los desafíos de ser una comunidad autónoma, lo cual ha forzado a gran parte de los moradores a buscar en la pesca, la ganadería y principalmente en el turismo los medios económicos de supervivencia y mantenimiento en la isla.

Tras la transferencia al Gobierno Provincial, bajo la condición de Distrito Estadual de la Provincia de Pernambuco, en 1988 el Decreto Presidencial no. 96.963 crea el Parque Nacional Mariño de Fernando de Noroña-PARNAMAR-, resguardando un área correspondiente al 70\% del total del Archipiélago, cuya administración compete al Instituto Brasileño del Medio Ambiente-IBAMA. Por su parte, el Gobierno de la Provincia de Pernambuco edita el Decreto Estadual no. 15.355, el 7 de abril de 1989, estableciendo como Área de Protección Ambiental (APA) el 100\% territorio del Archipiélago, y su gestión directa es asignada a una Administración General. La Tabla 2 resume la situación actual.

En conformidad con la evaluación facilitada por el Comp\&tenible Model, se verifica la existencia del Plan de Gestión del Archipiélago de Fernando de Noroña, Ecoturismo y Desarrollo Sostenible y que la visión en el expresada corresponde a criterios sostenibles. Del análisis realizado se desprende que Fernando de Noroña se encuentra en una fase de evolución, caracterizada como una situación en desarrollo en términos turísticos, conforme Tabla 2.

Tabla 2 - Desarrollo Turístico de Fernando de Noroña - Brasil

\begin{tabular}{|l|l|l|l|l|l|l|l|l|}
\hline $\begin{array}{l}\text { Resultados relativos } \\
\text { Elementos a valorar }\end{array}$ & $\mathbf{0}$ & $\mathbf{1}$ & $\mathbf{2}$ & $\mathbf{3}$ & $\mathbf{4}$ & $\mathbf{5}$ & Desarrollo Estratégico \\
\hline D1 & Visión de futuro - & & & & & & & $\begin{array}{l}\text { Visión nacional: destinos orientados por políticas y } \\
\text { planes autonómicos y regionales que imprimen una } \\
\text { visión de futuro propia. }\end{array}$ \\
\hline D2 & $\begin{array}{l}\text { Coherencia } \\
\text { cumplimiento- }\end{array}$ & & & & & & $\begin{array}{l}\text { El plan existe y sigue implementándose de forma } \\
\text { coherente con las orientaciones sostenibles, pero el } \\
\text { grado de ejecución de los programas y proyectos } \\
\text { están entre el 50\% y el 60\% de cumplimiento de los } \\
\text { objetivos, metas y cronograma de implantación. }\end{array}$ \\
\hline D3 & $\begin{array}{l}\text { Corrección y control } \\
-\end{array}$ & & & & & $\begin{array}{l}\text { El plan tiene previstos los mecanismos de } \\
\text { corrección y control de los procesos y resultados, } \\
\text { sin referencia a los impactos. El control sobre el } \\
\text { seguimiento es parcial. }\end{array}$ \\
\hline D4 & $\begin{array}{l}\text { Carácter estratégico } \\
-\end{array}$ & & & & $\begin{array}{l}\text { Planea y actúa a nivel estratégico, pero no fija con } \\
\text { claridad el modelo de desarrollo del destino, aunque } \\
\text { establezca criterios de actuación y mecanismos que } \\
\text { persiguen objetivos estratégicos. }\end{array}$ \\
\hline D5 & $\begin{array}{l}\text { Horizonte temporal } \\
-\end{array}$ & & & $\begin{array}{l}\text { El plan e implementación comprende un periodo } \\
\text { superior a 8 años para la consolidación del modelo } \\
\text { de desarrollo competenible en el destino. }\end{array}$ \\
\hline
\end{tabular}




\begin{tabular}{|c|c|c|c|}
\hline D6 & $\begin{array}{l}\text { Multidimensionalida } \\
\text { d estratégica - }\end{array}$ & & $\begin{array}{l}\text { Hay programas y proyectos derivados del plan } \\
\text { global dedicados al medio ambiente, a la sociedad y } \\
\text { cultura, así como a la economía del turismo local, } \\
\text { pero en cantidad y/o calidad insatisfactoria. }\end{array}$ \\
\hline D7 & $\begin{array}{l}\text { Gestión } \quad y \\
\text { organización - }\end{array}$ & & $\begin{array}{l}\text { Estado intermedio de organización y gestión, con } \\
\text { restricciones estructurales y organizacionales. }\end{array}$ \\
\hline D8 & $\begin{array}{l}\text { Financiación } \\
\text { turismo - }\end{array}$ & & $\begin{array}{l}\text { Hay pocos mecanismos y programas de inversión y } \\
\text { financiación externas, y la gestión del turismo no } \\
\text { recibe recursos de financiación conforme a sus } \\
\text { necesidades. }\end{array}$ \\
\hline D9 & $\begin{array}{l}\text { Coordinación } \\
\text { Cooperación - }\end{array}$ & & $\begin{array}{l}\text { El destino presenta relativa cooperación e } \\
\text { integración entre los agentes del turismo. Está } \\
\text { organizado en un forum regional, pero no posee } \\
\text { carácter deliberativo, sino consultivo, estando } \\
\text { habilitado apenas para opinar sobre el desarrollo } \\
\text { turístico del destino, sin decidir sobre él. }\end{array}$ \\
\hline \multicolumn{2}{|c|}{$\begin{array}{lll}\text { Desarrollo } & \text { Turístico } & \text { del } \\
\text { Destino FN } & & \\
\end{array}$} & Suma $=29$ puntos & $\begin{array}{l}\text { Entre } 15 \text { a } 29 \text { puntos = } \\
\text { Destino en Desarrollo (máximo } 45 \text { puntos) }\end{array}$ \\
\hline
\end{tabular}

Fuente: Elaboración propia (2005)

Esta fase actual puede ser considerada como de estructuración, pues están siendo trabajados principalmente los elementos del planeamiento y organización turística y que caracterizan un contexto de transición entre un estado desorganizado del turismo local, hacia una condición de profesionalización y fijación definitiva del turismo como actividad principal de sustento económico y como alternativa viable de desarrollo local sostenible (SUREDA ET AL, 1998; WEAVER, 2000).

Por la evidente exuberancia natural del archipiélago, por la necesidad de su preservación y por la fuerza de los dispositivos legales antes mencionados, se parte de la premisa de que el ecoturismo es la clave para el desarrollo local sustentable y, por lo tanto, es la actividad principal del archipiélago (GOVERNO DE PERNAMBUCO, 2001).

No obstante, algunos de los determinantes estratégicos necesarios para alcanzar la condición favorable hacia la competitividad global han sido ignorados, en gran parte debido al poco tiempo que lleva organizándose el turismo en base a políticas activas exclusivas para el Archipiélago. Los fallos estratégicos críticos están concentrados en lo referente a la coordinación, integración y cooperación entre los diversos agentes del turismo en el archipiélago y debe, por tanto, ser tratado como prioridad inmediata, para alcanzar y solidificar una situación de efectivo desarrollo turístico.

Sin embargo, pese a esos esfuerzos, se observa que a causa del relativo poco tiempo de incorporación del territorio al Estado de Pernambuco, por su característica insular y distancia del continente, por la tradición histórica de no ingerencia de la administración provincial en 
los asuntos del archipiélago, por la escasez de recursos financieros para atender las demandas del territorio, por la deseable pero inviable autosuficiencia de la administración local para satisfacer las necesidades comunitarias, Noroña todavía no ha alcanzando el conjunto de condiciones y objetivos deseados en una condición de desarrollo turístico.

Los motivos entre otros pueden ser la poca representatividad económica y electoral del territorio, las demandas de acción efectiva de coordinación y gestión aún irresueltas desde el ámbito del gobierno central y provincial, el que resulta en una relativa dificultad de articulación entre la Administración del Archipiélago con los demás agentes gubernamentales y sectoriales del Distrito, para abrir una brecha común, viable y sostenible para el desarrollo turístico.

La información y la comunicación como factores potencialmente capaces de superar este alejamiento son poco explotados y la ausencia o el error en los mensajes deriva una situación de conflicto ocasionada por intereses y visiones divergentes sobre el desarrollo turístico en el Archipiélago. Esta situación compromete el pacto necesario para un desarrollo turístico que albergue la capacidad de mejorar las condiciones de vida de la población, tal y como preconiza el factor D9, condicionado en gran parte por la capacidad de articulación, coordinación y cooperación entre los agentes del turismo.

En lo referente al tema financiación turística, Noroña intenta sobrevivir con su propia financiación. Las aportaciones del gobierno provincial son insuficientes, como ya ha sido comentado, en gran medida por la pequeña representatividad del Distrito. El mecanismo de financiación turística más importante proviene de la Tasa de Preservación Ambiental (TPA) que funciona también como un instrumento de política ambiental.

Por un lado, su finalidad es generar ingresos que garanticen la conservación de los ecosistemas, y por otro, es un mecanismo que incide sobre el comportamiento de los turistas, desfavoreciendo la prolongación de su estancia en el archipiélago. Además de la TPA, el Instituto Brasileño de Medio Ambiente (IBAMA), ha fijado otros impuestos recaudatorios que inciden sobre las actividades turísticas. Son los siguientes: Tasa de visita en el área del parque (recaudada por las empresas de buceo y transporte marítimo de pasajeros pero que son cobradas a los turistas); Tasa de circulación de coches en el área del parque; y Tasas de permiso de funcionamiento de establecimientos turísticos.

Sin embargo, el presupuesto necesario para la implementación integral del Plan y la financiación de programas y proyectos fundamentales para la incorporación definitiva del 
modelo sostenible de desarrollo turístico no es cubierto por las tasas recaudatorias. Existe un déficit de financiación turística interna y no hay mecanismos externos de financiación enderezados a satisfacer las demandas de inversión en el turismo en el archipiélago.

En lo tocante a la coherencia y cumplimiento del Plan, en el documento formal están previstos los mecanismos de corrección que permiten evaluar el avance en la implementación de las acciones necesarias para la adecuación del turismo a los criterios sostenibles, sin embargo, la mayoría de los programas y proyectos de implantación necesaria para la consolidación del turismo sostenible y competitivo no avanza, y los que avanzan, lo hacen muy despacio.

A modo de conclusión en lo referente a la dimensión de desarrollo turístico, Fernando de Noroña parece sufrir el síndrome del "plan de cajón”: existe un plan estratégico, cuyo contenido apunta a una visión de futuro enmarcada por la sostenibilidad del Archipiélago y en su formalización atiende a los reclamos sostenibles y competitivos. No obstante la buena intención del Plan, los factores relacionados con su implementación están muy por debajo del nivel recomendable. En definitiva, las acciones no corresponden a las intenciones, en gran parte por la falta de implicación y compromiso de todos los agentes.

Una síntesis de la dimensión desarrollo turístico permite verificar que el destino turístico de Fernando de Noroña presenta todas las condiciones para alcanzar un nivel de desarrollo turístico sostenible. Pero necesita mejorar el desempeño de factores que son imprescindibles, como la integración y cooperación entre los agentes del turismo local y la coherencia y cumplimiento de los planes ya elaborados. Del máximo de 45 puntos, Noroña ha logrado 29, lo que lo sitúa muy próximo a una situación de desarrollo turístico sostenible.

\subsection{Dimensión II - competitividad turística de Fernando de Noroña}

Por los recursos naturales e históricos que van a marcar la trayectoria distintiva de este destino turístico, Fernando de Noroña posee un fuerte reclamo atractivo. Del total de 21 islas, sólo una está habitada y su territorio es en su práctica totalidad Parque Nacional. La magia de las islas, el sol, las playas y su naturaleza salvaje son sus principales atributos, a ello hay que añadir que es uno de los mejores lugares para el buceo en el Atlántico, moldeado por un paisaje exuberante, que lo convierte en uno de los destinos brasileños más deseados y una de los más indicados para buceo en el mundo.

En efecto, esto exclusivo conjunto de recursos y atractivos turísticos que combina elementos naturales e histórico-culturales, potencian una ventajosa situación para definir atracciones incomparables y con ideales condiciones de proyectarse en el entorno competitivo, al mismo 
nivel de sus máximos competidores. Para enmarcar su fundamento turístico en los recursos y atractivos relacionados con el mar y la naturaleza, la preservación del medio ambiente es así el argumento más contundente para la implementación de proyectos turísticos en clave de sostenibilidad.

En la actualidad se explotan las siguientes actividades turísticas en el archipiélago: investigación científica; educación ambiental; educación histórico/cultural; contemplación paisajística de la flora y fauna terrestres y marítimas, a través de paseos a pie, en bicicleta, a caballo, paseos en barco, buceo; prácticas deportivas como surf, pesca deportiva, plana sub; ocio, dedicado a los baños de sol, de mar, fotografía y filmaciones y participación en eventos de animación turística o cultural.

Aunque a simple vista pueda parecer un elenco diversificado de actividades, en su mayoría no corresponden con las características relacionadas con el turismo activo, sino con el contemplativo. Lo cual contraria las expectativas de una demanda que suele reaccionar positivamente a los atractivos de destinos como puede ser Noroña (BUHALIS, 2000; HUDSON y MILLER, 2003). La mayoría de sus visitantes pertenecen a segmentos de mercado con renta elevada y en general se caracterizan por un buen nivel cultural y de dominio de la información, con disponibilidad y acostumbrado a disfrutar de un amplio abanico de actividades potenciadas por los atractivos del archipiélago, según lo indicado en la encuesta.

La Tabla 3. sintetiza la evaluación de Noroña en esta dimensión de análisis.

\section{Tabla 3 - Competitividad Turística de Fernando de Noroña}

\begin{tabular}{|c|c|c|c|c|c|c|c|c|}
\hline \multicolumn{2}{|c|}{$\begin{array}{l}\text { Elementos a valorar / } \\
\text { resultados relativos }\end{array}$} & $\mathbf{0}$ & 1 & 2 & 3 & 4 & 5 & Competitividad Estratégica \\
\hline C1 & $\begin{array}{l}\text { Recursos Turísticos } \\
-\end{array}$ & & & & & & 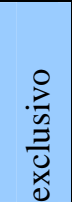 & $\begin{array}{l}\text { El destino presenta un exclusivo conjunto de } \\
\text { recursos y atractivos turísticos naturales, con } \\
\text { potencialidad de proyectarse en el entorno } \\
\text { competitivo, al nivel de sus máximos } \\
\text { competidores. }\end{array}$ \\
\hline C2 & $\begin{array}{l}\text { Actividades } \\
\text { disponibles - }\end{array}$ & & & 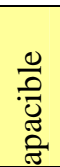 & & & & $\begin{array}{l}\text { El destino presenta un modesto conjunto de } \\
\text { actividades, debido a la incapacidad inventiva } \\
\text { y creativa de la gestión. }\end{array}$ \\
\hline C3 & $\begin{array}{ll}\text { Equipamientos } & \text { y } \\
\text { servicios - } & \end{array}$ & 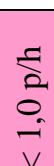 & & & & & & $\begin{array}{l}\text { Destinos cuya oferta registra un índice de } \\
\text { plaza/alojamiento reglada inferior a } 1 \text { para } \\
\text { cada habitante de derecho en el destino. }\end{array}$ \\
\hline
\end{tabular}




\begin{tabular}{|c|c|c|c|c|c|c|c|c|}
\hline $\mathrm{C4}$ & Infraestructura - & & & 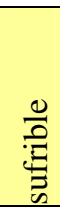 & & & & $\begin{array}{l}\text { La infraestructura turística es escasa y presenta } \\
\text { indicios contundentes de agotamiento en la } \\
\text { dimensión y en el mantenimiento. Presenta } \\
\text { fallos en diversos criterios. }\end{array}$ \\
\hline C5 & $\begin{array}{l}\text { Marketing } \\
\text { Responsable - }\end{array}$ & & $\begin{array}{l}\frac{\text { त }}{2} \\
\text { : } \\
\text { ज }\end{array}$ & & & & & $\begin{array}{l}\text { La comunicación turística no posiciona el } \\
\text { destino en bases sostenibles. No define la } \\
\text { política de valor y precios. Se ocupa de } \\
\text { la comercialización y la promoción turística. }\end{array}$ \\
\hline C6 & Estacionalidad - & & & & 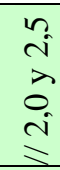 & & & $\begin{array}{l}\text { El número total de turistas en el mes de } \\
\text { máximo flujo presenta una variación entre } 2,0 \\
\text { y } 2,5 \text { veces mayor que el número total de } \\
\text { turistas en el mes de menor flujo en el destino. }\end{array}$ \\
\hline C7 & Rentabilidad - & & & & 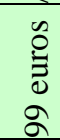 & & & $\begin{array}{l}\text { Nivel de gasto promedio por turista/día de } 99 \\
\text { euros, conforme cambio de } 1 \text { euro }=2,90 \\
\text { Reais. }\end{array}$ \\
\hline $\mathbf{C 8}$ & $\begin{array}{l}\text { Capacidad de } \\
\text { Retención - }\end{array}$ & & & & & & n & $\begin{array}{l}\text { Índices de estancia media superior a } 5 \text { días de } \\
\text { permanencia del turista en el destino. }\end{array}$ \\
\hline C9 & $\begin{array}{l}\text { Satisfacción del } \\
\text { Visitante - }\end{array}$ & 员 & 오 & 8 & $R$ & $\infty$ & 8 & $\begin{array}{l}\text { Niveles de satisfacción del turista con la } \\
\text { experiencia de viaje en el destino superior al } \\
80 \% \text {. }\end{array}$ \\
\hline \multicolumn{2}{|c|}{$\begin{array}{l}\text { Competitividad Turística } \\
\text { de FN }\end{array}$} & \multicolumn{6}{|c|}{25 puntos } & $\begin{array}{l}\text { Entre } 15 \text { y } 29 \text { puntos = } \\
\text { Competitividad Moderada }\end{array}$ \\
\hline
\end{tabular}

Fuente: Elaboración propia (2005)

Esto significa que no se están aplicando los principios de la oferta combinada, no se está explotando la variedad y diversidad de actividades y entretenimiento potenciales dados los recursos y atractivos del archipiélago, hecho confirmado por un 58\% de los encuestados por su deseo de practicar otras actividades recreativas en la isla, proponiendo diferentes modalidades de turismo activo como paseos de ultra leve, parapente, natación con delfines, pesca oceánica, rapel, escalada, esquí, windsurf, surf, skysurf y una gran diversidad de deportes de aventura y naturaleza que les gustaría practicar.

Noroña atiende con excelencia al público a través de su principal atractivo, el buceo, que concentra gran parte de la oferta del que hacer en la estancia. Sin embargo, no es la principal motivación para visitar la isla, pues el 87\% de los encuestados declaran estar interesados en el “turismo en general”, lo que significa disponibilidad para participar en un amplio rango de actividades todavía por explotar. Este es uno de los indicadores más contundentes de un conjunto de actividades rezagadas en sus potenciales. Las oportunidades están claras y el ambiente competitivo exige una postura emprendedora, sobre todo cuando se dispone de tan preciados recursos. Hay que recordar que Noroña está ubicado en una región ecuatorial, con unas condiciones climáticas y atmosféricas muy apropiadas para el disfrute de una gran diversidad de actividades durante todos los meses del año. Algo que tiene, obviamente, 
implicaciones decisivas en los desequilibrios estacionales típicos de la actividad turística y desafío a los gestores.

Tampoco los equipamientos de alojamiento y restauración son satisfactorios. La conformación de un modelo de hospedaría residencial basado en la informalidad -acoger al turista en el propio hogar- ha derivado en un absoluto anacronismo de la oferta de alojamiento en la isla que, agravada por la avidez de aumentar la capacidad receptora de los establecimientos sin base a criterios competitivos, no garantiza acomodaciones de calidad para sus clientes y evidencia la completa desatención por aspectos arquitectónicos, paisajísticos y medioambientales. Este criterio se ha revelado como elemento negativo en la evaluación de la oferta de equipamientos y servicios en la isla.

Este sistema de alojamiento ha perdurado dada la inexistencia de alternativas de más calidad y por las características de un turismo que es invitado a disfrutar todo el día al aire libre, por tanto, alejado de las hospederías, entendidas como lugares que ofrecen un servicio elemental de cama y desayuno, pero sin ninguna orientación en cuanto a criterios colectivos de calidad y servicios. Luego el alojamiento en Noroña no está caracterizado como un atractivo en sí mismo, algo que podría motivar una ampliación del periodo de estancia y mejorar la percepción de calidad del turista.

Los turistas eligen Noroña motivados por el paraíso natural, pero su expectativa es encontrar una combinación coherente entre exuberancia natural y un mínimo de conforto y ambientación estética. A un proyecto sostenible, han de corresponder estructuras y servicios que acaten rigurosos criterios de adaptación a las condiciones y características locales, lo cual no sucede en la isla. Los equipos no siguen un patrón de calidad, hay insuficientes programas de fomento para el perfeccionamiento de los servicios, se hace un uso intensivo de tecnologías insostenibles (coches, energía termoeléctrica, consumo excéntrico, etc.).

Equipamientos de alojamiento recientemente construidos, conscientes de la necesidad de mejorar los servicios bajo un criterio de competitividad del destino, buscan adaptar sus instalaciones a los criterios de calidad establecidos en base a las características, potencialidades y restricciones locales. Para capacitar los equipamientos ya existentes, desde 2001, ha sido implantado un programa de adecuación y capacitación de estos equipamientos que será detallado en un apartado posterior.

A pesar del elevado nivel de satisfacción, el porcentaje de turistas insatisfechos es competitivamente preocupante pues el ambiente sugiere que "para fidelizar hay que 
sorprender”. Es notorio el hecho de que todos los factores de insatisfacción apuntados están faltos de acciones de gestión y que pueden ser revertidos en elementos positivos de valoración.

En resumen, respecto a la Dimensión II Noroña alcanza 25 puntos, lo que lo sitúa como un destino con nivel de competitividad turística moderada, en gran parte por ese potencial aú no explotado conforme a lo revelado por los factores de oferta analizados por el Competenible Model. El destino presenta todas las condiciones previas para poder pasar de una competitividad moderada a una situación de referencia para sus competidores.

\subsection{Dimensión III - sostenibilidad turística de Fernando de Noroña}

La dimensión sostenibilidad turística se preocupa por los impactos más amplios del turismo sobre el ambiente y la sociedad en un horizonte temporal a largo plazo. El impacto es la consecuencia de la relación causa-efecto ya comentada en los criterios de eficiencia. En general, está relacionado a posibles transformaciones que pueden venir a sufrir determinado sistema a causa de interferencias externas deliberadas.

Diferentemente de los resultados, que revelan un momento determinado, los impactos solo pueden ser evaluados por indicadores que permitan analizar la evolución del comportamiento del factor en el tiempo, considerando que efectos de largo-plazo solamente pueden hallarse tras pasado esto largo plazo, y a partir de un punto de referencia en el pasado (OMT, 1997).

Las condiciones de Sostenibilidad Turística del destino Noroña se evalúa por medio de los factores relacionados a las dimensiones medioambiental y social, conforme síntesis en la Tabla 4.

\section{Tabla 4 - Sostenibilidad Turística de Fernando de Noroña}

\begin{tabular}{|c|c|c|c|c|c|c|c|c|}
\hline \multicolumn{2}{|c|}{$\begin{array}{r}\text { Elementos a valorar / } \\
\text { escores relativos }\end{array}$} & $\mathbf{0}$ & 1 & 2 & 3 & 4 & 5 & Sostenibilidad Turística \\
\hline S1 & $\begin{array}{l}\text { Subdimensión } \\
\text { Medioambiental- }\end{array}$ & & & & & & อ̊ำ & $\begin{array}{l}70 \% \text { del territorio es Parque Nacional } \\
\text { Mariño e } 30 \% \text { APA }\end{array}$ \\
\hline S1.1 & Agua - & & & & & & & $\begin{array}{l}\text { índices de consumo de agua y despilfarro } \\
\text { ascendentes y índices de reutilización y } \\
\text { tratamiento son estables. }\end{array}$ \\
\hline S1.2 & Energia - & & 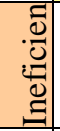 & & & & & $\begin{array}{l}\text { Matriz energética insostenible y no hay } \\
\text { registro de uso de energías limpias por el } \\
\text { sector. }\end{array}$ \\
\hline S1.3 & Producción Limpia - & $\frac{ت}{\widetilde{Z}}$ & & & & & & $\begin{array}{l}\text { No hay transporte publico y predomina el } \\
\text { uso del coche; no hay alternativas }\end{array}$ \\
\hline
\end{tabular}




\begin{tabular}{|c|c|c|c|c|c|c|}
\hline S1.4 & Transporte - & & & & & $\begin{array}{l}\text { sistemas de gestión ambiental insuficiente } \\
\text { y pocas iniciativas conjuntas de } \\
\text { autorregulación }\end{array}$ \\
\hline S1.5 & Urbanismo y Paisaje - & & : & & & $\begin{array}{l}\text { Desatención e inadecuación de los } \\
\text { equipamientos }\end{array}$ \\
\hline S1.6 & Arquitectura y Entorno - & & 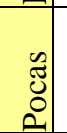 & & & $\begin{array}{l}\text { Plan Director en pocas áreas de interés } \\
\text { turístico, conflictos en el reglamento para } \\
\text { ocupación del territorio. }\end{array}$ \\
\hline $\begin{array}{l}\text { Suma } \\
\text { Noro } \\
\text { máxir }\end{array}$ & $\begin{array}{l}\text { parcial medio ambiente en } \\
\text { de } 35 \text { puntos }\end{array}$ & $14 \mathrm{pu}$ & ntos & & & $\begin{array}{l}\text { Fuerte: }=>25 \text { puntos } \\
\text { Moderada: } 12 \text { a } 24 \text { puntos } \\
\text { Débil: }<11 \text { puntos }\end{array}$ \\
\hline S2 & SubDimensión Social - & & & & 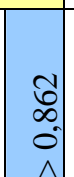 & $\begin{array}{l}\text { Niveles de desarrollo humano y de } \\
\text { seguridad satisfactorios, sin grandes } \\
\text { contrastes en la estructura socio- } \\
\text { económica del local. }\end{array}$ \\
\hline S2.1 & Cultura y Patrimonio - & & & & & $\begin{array}{l}\text { Recursos patrimoniales cuidados, pero sin } \\
\text { nuevas intervenciones }\end{array}$ \\
\hline S2.2 & Participación Ciudadana - & & 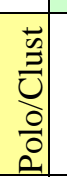 & & & $\begin{array}{l}\text { Administración no electa con problemas } \\
\text { de legitimidad; hay una asamblea popular } \\
\text { como representación ciudadana, pero no } \\
\text { es deliberativa }\end{array}$ \\
\hline S2.3 & Capacitación Turística - & 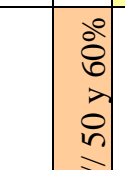 & & & & $\begin{array}{l}\text { Pocas personas están capacitadas en nivel } \\
\text { adecuado al ejercicio de las funciones y de } \\
\text { la toma de decisiones exigida por su } \\
\text { cargo. }\end{array}$ \\
\hline S2.4 & Empleo y Ocupación - & & & s & & $\begin{array}{l}\text { Entre } 70 \% \text { y } 80 \% \text { del personal empleado } \\
\text { en los negocios turísticos. }\end{array}$ \\
\hline S2.5 & Rendimiento - & & & ठे & & $\begin{array}{l}\text { sueldo anual promedio en el sector } \\
\text { turístico es un } 30 \% \text { mayor de los } \\
\text { empleados en otras actividades }\end{array}$ \\
\hline S2.6 & Beneficios - & & & & & $\begin{array}{l}\text { Participación relativa entre } 30 \% \text { y } 40 \% \text { de } \\
\text { negocios de origen local y regional en el } \\
\text { suministro de las actividades turísticas. }\end{array}$ \\
\hline S2.7 & PIB Turístico - & & & & & $\begin{array}{l}\text { Contribución de las actividades turísticas } \\
\text { al PIB local entre un } 40 \text { y } 50 \% \text {. }\end{array}$ \\
\hline S2.8 & Satisfacción del residente - & & & & 官 & $\begin{array}{l}\text { Niveles de satisfacción superiores en un } \\
80 \% \text {. }\end{array}$ \\
\hline \multicolumn{2}{|c|}{$\begin{array}{l}\text { Suma parcial: } \\
\text { Subdimensión Social - S2 } \\
\text { - máximo } 45 \text { puntos - }\end{array}$} & \multicolumn{4}{|c|}{ Total 33 puntos } & $\begin{array}{l}\text { Sostenibilidad Moderada = entre } 18 \text { y } 34 \\
\text { puntos }\end{array}$ \\
\hline \multicolumn{2}{|c|}{$\begin{array}{l}\text { Suma Total Sostenibilidad } \\
\text { - máximo } 80 \text { puntos - }\end{array}$} & \multicolumn{4}{|c|}{ Total 47 puntos } & $\begin{array}{l}\text { Sostenibilidad Estratégica Moderada }= \\
\text { entre } 30 \text { y } 60 \text { puntos }\end{array}$ \\
\hline
\end{tabular}

Fuente: Elaboración propia (2005)

Se puede verificar que respecto a la Dimensión III, que representa la sostenibilidad turística, el destino Fernando de Noroña contabiliza 47 puntos, lo que se lo clasifica como mejorable, pues revela una condición de sostenibilidad turística moderada. Hay que destacar las discrepancias entre los factores -unos muy positivos y otros muy deficitarios. 
En cuanto a la sostenibilidad social, del máximo de 45 puntos que puede sumar un destino, Noroña alcanza 33 puntos, según el Competenible Model, lo que describe una situación de sostenibilidad social moderada, que a diferencia de la sostenibilidad ambiental, está más cercana a los referentes sostenibles de un estado de desarrollo pleno y satisfactorio.

Para controlar el impacto del turismo la entrada de visitantes en la isla está limitada a 450 turistas/día. Sin embargo, quedan fuera de este límite de personas, aquellas que llegan por motivo de trabajo (que son muchas) y, por el registro de ocupación integral en determinadas fechas de las plazas de alojamiento regladas que suman 1.347, se deduce que esta capacidad no está siendo respetada, lo que le anula toda y cualquier función reguladora. El flujo turístico ha duplicado en la última década y ha superado los 60 mil en el año 2007, demostrando una extraordinaria evolución ascendente.

Es notoria una relevante presión demográfica sobre el medio ambiente isleño. Como es evidente, el agua y la energía no son recursos abundantes y la presión sobre el medio ambiente crece significativamente, lo que lleva a una situación de eco ineficiencia generalizada en la isla.

\subsection{Sostenibilidad estratégica: valoración global del destino Fernando de Noroña}

En la Interpretación de la valoración global del destino que equivale a la situación de sostenibilidad estratégica, según el Comp\&tenible Model, Noroña alcanza 101 puntos del total de 170, lo que lo clasifica como un destino en situación moderada de cara a los condicionantes competitivos y sostenibles representados por los factores evaluados. El análisis permite inferir que la mayoría de los criterios mejorables están pendientes de programas de acción a cargo de la gestión del destino de forma integrada y cooperativa.

La Sostenibilidad Estratégica de Noroña, se resume en la Tabla 5.

Tabla 5 - Sostenibilidad Estratégica de Fernando de Noroña

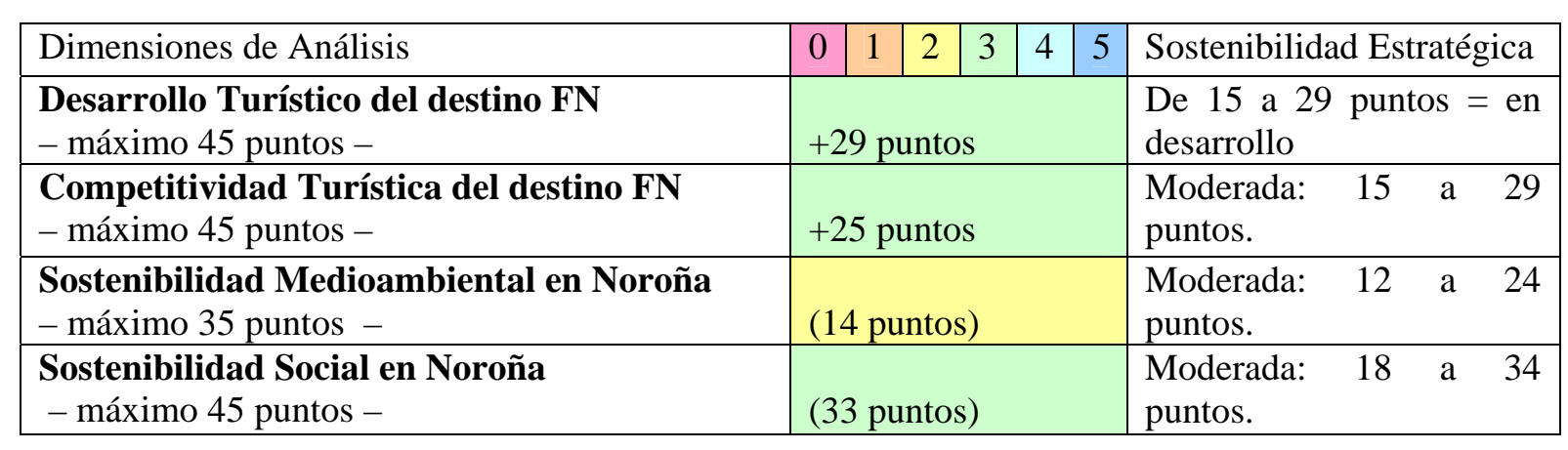




\begin{tabular}{|l|l|llll|}
\hline $\begin{array}{l}\text { Suma parcial Sostenibilidad Turística } \\
- \text { máximo } 80 \text { puntos }-\end{array}$ & +47 puntos & $\begin{array}{l}\text { Moderada: } \\
\text { puntos. }\end{array}$ & a & 60 \\
\hline $\begin{array}{l}\text { Suma total Sostenibilidad Estratégica } \\
\text { - máximo } 170 \text { puntos }-\end{array}$ & $=101$ puntos & $\begin{array}{l}\text { Moderada: } \\
\text { puntos. }\end{array}$ & a & 119 \\
\hline
\end{tabular}

Fuente: Elaboración propia (2005)

Evaluando el caso del destino de Fernando de Noroña por el prisma del modelo, se puede concluir que hay una concepción teórica de turismo ecológico de pretensión sostenible que no se transmite en la oferta efectiva que experimenta el turista, a razón de los desajustes en la calidad de los servicios, en la estructura básica de alojamiento y en los tipos de actividades ofertadas al visitante. De forma general, los motivos de insatisfacción tienen grandes posibilidades de eliminación con acciones contundentes de gestión del destino.

\section{Conclusiones}

Considerando que los destinos turísticos tienden a utilizar instrumentos de planificación y gestión cada vez más a menudo para alcanzar retos de competitividad y de sostenibilidad, la proposición de sistemas e instrumentos de seguimiento de las estrategias y acciones es, pues, necesaria y, en este sentido, el Comp\&tenible Model puede representar una metodología útil y eficaz.

La aplicación del Comp\&tenible Model permite analizar datos de caracterización y desempeño turísticos de determinado destino, evaluando la realidad de las condiciones de actuación en el mercado y las perspectivas hacia el futuro, interpretada por medio de factores e indicadores representativos del sistema turístico, definidos en base a condicionantes consolidados por el escenario y entorno para la gestión y estructuración de la oferta turística de destinos que compiten, o aspiran competir, orientados por la sostenibilidad estratégica.

De todo lo anterior, se puede deducir que el modelo aquí denominado Competenible Model permite una evaluación eficaz, segura y suficientemente amplia de la situación de un destino turístico desde el punto de vista de la sostenibilidad y de su capacidad competitiva, a la vez que permite la comparación entre destinos turísticos que compiten en un mismo segmento de la demanda turística.

En base a la aplicación de la metodología se puede hallar que el destino turístico Fernando de Noronha atiende en parte a los determinantes competitivos y sostenibles implicados en la evaluación. Con referencia a su validación como metodología analítica, los resultados facilitados por el modelo permiten obtener un diagnostico detallado del destino y apunta con 
precisión cuales son los atributos críticos de observación y acción a cabo de la gestión del destino y en acorde a los retos y expectativas con el turismo local.

La atribución de estas valoraciones es en gran parte subjetiva, pues hasta el momento no se ha encontrado modelos confiables o integrales de evaluación objetiva de competitividad sistémica del desarrollo turístico bajo los criterios sostenibles. No obstante, la grande función de los índices es presentar a los interesados una forma de evaluación un poco más estructurada y que sea pasible de comparación entre destinos, y que mismo a pesar das sus limitaciones, posibilita la identificación de los gaps competitivos y de las prioridades de acción estratégica.

\section{Referencias}

BOSCH Campubri, R. et al.1998 . Turismo e Meio Ambiente. Centro de Estúdios Ramon Areces. Madrid.

BROWN, D. 1994. Facilitating Conceptual Change Using Analogies and Explanatory Models. International Journal of Science Education, 16 ( $\mathrm{n}^{\circ}$ 2), 201-214.

BUHALIS, D. 2000. Marketing the competitive destination of the future. Tourism Management. V. 21, Issue 1, pp. 97-116.

CROUCH, G. I., \& RITCHIE, B. J. R. 1999. Tourism, competitiveness, and societal prosperity. Journal of Business Research, Vol.44, No.3, 137-152.

GO, F. y GOVERS, R. 2000. Integrated quality management for tourist destinations: a European perspective on achieving competitiveness. Tourism Management, Vol. 21, No. 1, pp. 79-88.

GILBERT, J. y BOULTER, C. 1995. Learning science through models and modelling. In Frazer, B. \& Tobin, K. (Eds). The International Handbook of Science Education. Dordrecht, Kluwer. Disponible en: http://www.moebio.uchile.cl

GOODE, W.J. y HATT, P.K. 1977. Métodos em pesquisa social. 6a. Ed. São Paulo, Editora Nacional.

GOOROOCHURN, N. y SUGIYARTO, G. 2003. Competitiveness indicators in the travel and tourism industry. Tourism and Travel Research Institute. Nottingham, G8 1BB, England. Disponible en: http://www.scottishexecutive.gov.uk/library3/tourism/tfar-05.asp. Consultado en nov.2004

GOVERNO DE PERNAMBUCO. 2001. Projeto de Uso e Ocupação do Solo em Fernando de Noronha. Distrito E. de F. de Noronha. Recife (Brasil).

HUDSON, S. y MILLER, G.A. 2003. The responsible marketing of tourism: the case of Canadian

Mountain Holidays. Tourism Management. Disponible en www.sciencedirect.com. Consutado en ago. 2003

JACOBS, M. 1997. La economía verde: medio ambiente, desarrollo sostenible y la política del futuro. Icaria. Barcelona.

LEE, Kian Foh. 2001. Sustainable tourism destinations: the importance of cleaner production. Journal of Cleaner Production 9, 313-323.

MAZARO, R.M. y VARZIN, G. 2008. Modelos de Competitividad de Destinos Turísticos en el Marco de la Sostenibilidad. Revista de Administração Contemporânea-RAC, Curitiba, v. 12, n. 3, p. 789-809, Jul./Set. 
MAZARO, R.M. 2006. Competitividad de Destinos Turisticos y Sostenibilidad Estratégica. Proposición de um modelo de evaluación de condiciones y factores determinantes. Tese de Doutorado. Faculdade de Ciencias Economicas e Empresariais, Universidade de Barcelona -UB, Espanha. Barcelona.

MIHALIC, Tanja. 2000. Environmental management of a tourist destination: a factor of tourism competitiveness. Tourism Management 21, 65-78.

OCDE. 1992. Organización para la Coordinación y Desarrollo Económico World Competitiveness Report: World Economic Forum and IMD International, Lausanne, Switzerland. 1992. Disponible en www.ocde.org. Consultado en abr.2003.

OMT. 1997. Guía práctica para el desarrollo y uso de indicadores de turismo sostenible. OMT, Madrid.

OMT. 2000. Turismo panorama 2020: Nuevas previsiones. OMT. Madrid.

QUIVY, R. y CAMPENHOUDT, L.V. 1998. Manual de Investigação em Ciências Sociais. Lisboa: Gradiva.

RITCHIE, J.R.B. y CROUCH, G.I. 2003. The competitive destination: a sustainability perspective. CAB International Publishing. Wallingford.

SUREDA ET AL. 1998. La competitividad turística del municipio. Estudios de Gestión Turística. CEDIT-ESADE. N. 3, febrero.

VALLS, J. F. 2004. Gestión de Destinos Turísticos Sostenibles. Barcelona: Gestión 2000, 2004.

WEAVER, David B. 2000. A broad context model of destination development scenarios. Tourism Management. Volume 21, Issue 3, June. Pages 217-224, 2000.

WTTC - World Travel and Tourism Council. 2004. The WTTC Report: Blueprint for New Tourism. Disponible en http://www.wttc.org/blueprint/WTTCBlueprintFinal.pdf. 2004. Consultado en jan.2005.

Recebido em: 25/11/2008

Aprovado em: 02/02/2009 